\title{
Perception and Demonstratives a
}

\author{
Imogen Dickie
}

The Oxford Handbook of Philosophy of Perception

Edited by Mohan Matthen

Print Publication Date: Jul 2015 Subject: Philosophy, Philosophy of Mind

Online Publication Date: Jun 2014 DOI: 10.1093/oxfordhb/9780199600472.013.041

\section{Abstract and Keywords}

A 'perceptual demonstrative' thought is a thought of the kind standardly made available by a perceptual link with an object, and standardly expressed using 'this' or that'. This chapter is an introduction to a range of questions about how perception of objects enables us to form perceptual demonstrative thoughts about them.

Keywords: perceptual demonstratives, acquaintance, reference

THIS chapter is about the relationship between perception and perceptual demonstrative thought. A 'perceptual demonstrative thought' is a thought standardly made available by a perceptual link with an object in the external world, and standardly expressed using the demonstratives 'this' or 'that'. For example, the thought you express when you say 'That is rolling', looking at an orange rolling along the table in front of you in an ordinary situation, is a central case of perceptual demonstrative thought. The class of perceptual demonstrative thoughts includes this kind of central case and other thoughts relevantly similar to it. (What counts as a 'relevant' similarity will emerge as we go on.)

The definition of 'perceptual demonstrative thought' supposes that, in central cases, your perceptual link with an external-world object does enable you to think about it. (This sets aside various extreme views from the history of discussion of the relationship between perception and thought. For example it sets aside 'idealist' views, according to which perception enables us to think only about mind-dependent entities. ${ }^{1}$ And it sets aside 'inscrutability' views, according to which there is no fact of the matter as to which object a thought is about, or whether it is about an object at all. ${ }^{2}$ ) But to insist that, in this kind of case, a perceptual link does enable thought about an external-world object is to say nothing about how it does. This question-the question of how a perceptual link with an object enables perceptual demonstrative thought about it-is the fundamental question that an account of the relation between perception and perceptual demonstrative thought must address. 


\section{Perception and Demonstratives}

To keep to handbook-entry scale, I shall restrict the discussion to the question as it arises for visual perception: How does a visual perceptual link with an object enable perceptual demonstrative thought about it? (The philosophical literature on perceptual demonstrative (p. 834) thought has developed around vision. ${ }^{3}$ There are hard questions about how closely perceptual demonstrative thought in other modalities parallels the visual case.)

The chapter has three sections. Section 1 elucidates the fundamental question by sketching some of the traditional and contemporary puzzles that accompany it. Section 2 lays out the contrast between 'acquaintance theoretic' and 'description theoretic' responses to the fundamental question and the associated puzzles. Section 3 is about how a traditional view of the nature of perception has skewed the acquaintance vs. description discussion. Section 4 shows how recent advances in our understanding of perception-advances away from the traditional view-shift the ground on which the debate about perception and demonstratives must take place.

\section{Some Puzzles about Perceptual Demonstra- tive Thought}

Recall the example of perceptual demonstrative thought with which we began. You are looking at an orange rolling along a table in front of you in a situation devoid of perceptual or cognitive perversity-no mirrors, distorting lenses, or unusual lighting; no worries about whether you are a brain in a vat-and thinking the thought you would express by saying 'That is rolling'. We are supposing that in this case your perceptual link with the orange does enable you to think about it. The fundamental question for an account of the relation between perception and demonstratives is the question of how your perceptual link is doing its aboutness-fixing and thought-enabling work. But many philosophers have thought it best to approach the fundamental question against the background of a range of puzzles or subsidiary questions which bring out the kinds of commitment that an answer to the central question might carry. This section sketches seven of these puzzles.

\section{First puzzle-directness ${ }^{4}$}

The first puzzle concerns how direct in space, time, and causal pathway a perceptual link must be if it is to enable perceptual demonstrative thought. Let us say that a 'perceptual link' with an object is a perceptual information feed whose deliverances are sensitive to the object's properties. Then all of the following count as cases where subject $S$ has a perceptual link with object $o$ :

(1) a central case situation of the kind we started with ( $\mathrm{S}$ is looking at $o$ as $o$ rolls along a table a couple of feet away).

(2) $\mathrm{S}$ is looking at $o$ in a mirror. (p. 835)

(3) $\mathrm{S}$ is looking at $o$ 's shadow.

(4) $\mathrm{S}$ is looking at $o$ on live television. 


\section{Perception and Demonstratives}

(5) $\mathrm{S}$ is looking at a now long-dead person on film; the film shows the person still in her prime

(6) $\mathrm{S}$ is looking at a bright, reddish, star which in fact ceased to exist 500 years ago, but is still visible to $S$ because it was 1,000 light years away.

(7) $\mathrm{S}$ is looking at some $o^{*}$ many of whose properties depend causally on $o^{\prime}$ ( for example, $o^{\prime}$ s footprint in the sand).

(8) $\mathrm{S}$ is looking at some $o^{*}$ only a few of whose properties depend causally on $o^{\prime}$ ' (for example, S might be looking at $o$ 's car, inexpertly parked by $o$, and now festooned with parking tickets, and thinking 'He'll be sorry').

Let us say that in (1) - the central case situation-S's perceptual link with $o$ is 'maximally direct': it is as direct in space, time, and causal pathway as our perceptual links get. Then (2)-(8) describe various kinds and degrees of progression away from maximal directness. Most participants in the debate about perception and demonstratives agree that the perceptual links at (7) and (8) cannot sustain perceptual demonstrative thought. These perceptual links are too indirect to put $\mathrm{S}$ in a position to think about $o$ in the same way as the perceptual link at (1) does (they enable $S$ to think about $o$, but only under the descriptions 'the maker of this footprint' or 'the driver of that car'). But (2)-(6) describe a continuum of situations in which S's perceptual link with $o$ is less and less direct. Where along this continuum does a perceptual link with an object become too indirect to enable perceptual demonstrative thought about it?

\section{Second puzzle-comprehensiveness ${ }^{5}$}

The second puzzle is about how much of a thing a perceptual link must put you in contact with to enable perceptual demonstrative thought about it. On the face of things, it seems that a central-case perceptual link does not put you in touch with an entire ordinary object. Ordinary objects extend in three dimensions. But your eyes pick up only light reflected by the surfaces of the object that face you. So (it seems) there are reasonable grounds for saying that there are parts of the object (its interior; its back surfaces) with which your perceptual link is not putting you in contact. ${ }^{6}$ But it is also plausible that the thought you express when you say 'That is rolling' in the central case we have described is about the whole orange, not just the part of it that faces you. So it seems that in central-case perceptual demonstrative thought, perceptual contact with part of a thing enables perceptual demonstrative thought about all of it. And in that case we should be able to say how much of a thing a perceptual link must put you in contact with-how much of the thing the perceptual link must comprehend-if it is to sustain perceptual demonstrative thought. Can $S$ have a perceptual demonstrative thought about a whole fence-post on the basis of a (p. 836) perceptual link that comprehends only the part of the post that sticks up above the ground? Does a perceptual link that comprehends only the tip of a fog-bound peninsula put you in a position to have a perceptual demonstrative thought about a whole continent? 


\section{Perception and Demonstratives}

Note that this is another continuum puzzle. There is a continuum running from the central case to something like the peninsula/continent case. We should be able to say how far along this continuum the class of perceptual links that can sustain perceptual demonstrative thought extends.

\section{Third puzzle-classification}

The third puzzle concerns the relation between perceptual demonstrative reference and sortal classification. In intuitive terms, 'sortal' classification is classification of objects according to the kinds of objects they are. For example, ' $\mathrm{X}$ is an animal', ' $\mathrm{X}$ is a tree', and ' $\mathrm{X}$ is an item of furniture' are all statements of sortal classification because 'animal', 'tree', and 'item of furniture' are all kinds in some intuitive sense of 'kind'. ' $\mathrm{X}$ is red' is not a statement of sortal classification because it does not carry genuine kind information: to tell you that $\mathrm{X}$ is red is not yet to tell you anything about how $\mathrm{X}$ might have come into existence; how it might change over time; or the kind of event that would destroy it. (There are very hard questions about how the intuitive notion of 'sortal' classification is to be made precise. ${ }^{7}$ )

The puzzle about perceptual demonstrative thought and sortal classification arises because there are apparently strong grounds for both the ('sortalist') claim that a perceptual link enables perceptual demonstrative thought only if it enables sortal classification and the competing ('anti-sortalist') claim that a perceptual link can enable perceptual demonstrative thought about an object without even in principle putting the subject in a position to know what kind of thing it is.

One argument for sortalism comes from the old contention that any scene perception might present can be divided up into objects in different ways, and it is only by supplying a sortal concept that you can isolate one of the objects in a scene as the thing you are going to go on and think about. For example, looking at a stand of trees you might think each of 'Here is a copse', 'Here are five trees', or 'Here are thousands of leaves, dozens of branches, and five trunks'. According to the sortalist, your perceptual feed alone cannot do the job of determining whether you are thinking about the copse, the trees, or the leaves and branches. Rather, you must supply a sortal concept ('copse', 'tree', 'branch') to determine which of the things in the perceived scene is the object of your perceptual demonstrative thought. ${ }^{8}$

The main grounds for anti-sortalism come from apparent counterexamples to sortalism: cases where a perceptual link seems to enable perceptual demonstrative thought without enabling sortal classification. Here are some examples of this kind. ${ }^{9}$

CASE 1-You stumble upon a thing of a kind you have not come across before. You have no idea where it might fit in your system of sortal classification-whether it is animal, (p. 837) vegetable, or mineral; whether it is an artefact or something that came to exist without human intervention. But surely (it seems) your perceptual link is enabling you to think about it (there it is, sitting on your desk, and you are thinking 'I wonder what this thing is'). 


\section{Perception and Demonstratives}

CASE 2-You think (looking at $o$ and noting $o$ 's tallness-for-a-man) 'That is a tall man'. In fact, $o$ is a waxwork. But surely (it seems) your perceptual link is securing $o$ as the object your thought is about.

CASE 3-You can see a thing moving around in the distance. It is too far away for you to tell what kind of thing it is. But surely (it seems) you can think about it. (You and your friend might be having a dispute about whether it is a bird, a plane, or Superman.)

The standard sortalist response to cases like these ${ }^{10}$ is to say that perceptual demonstrative thought does not require a right sortal classification of the object the thought is about. A perceptual link that enables perceptual demonstrative thought need only enable the subject to make an approximately right classification. Or, alternatively, it need only supply the subject with the in principle capacity to home in on a right classification. But anyone making this move faces difficult questions. How is the notion of 'approximating to' or 'homing in on' a right sortal classification to be made precise? Does the move work against all of the examples the anti-sortalist might raise? Does the weakened sortalist view respect the arguments that motivate sortalism in the first place?

A right account of how perception enables perceptual demonstrative thought should enable us to settle the sortalist/ anti-sortalist dispute.

\section{Fourth puzzle-category ${ }^{11}$}

The fourth puzzle concerns the category of particular about which perceptual demonstrative thought is possible. In the central-case example we started with, the perceptual demonstrative thought is about an ordinary material thing. But does the class of things about which we can have this kind of thought include non-ordinary physical things like ripples, clouds, and shadows? Does it include mereological gryphons built from parts of distinct material objects (so that a suitable perceptual link could enable me to have 'that' thoughts about the mereological sum of my dog's left ear and a tree in the middle distance)? What about places, times, and events-can a perceptual feed enable a subject to think about these particulars in the same way as it enables us to think about ordinary material things in central cases?

\section{Fifth puzzle-focus ${ }^{12}$}

The fifth puzzle is (roughly) the puzzle of whether there can be perceptual demonstrative thought on the basis of merely peripheral vision (strictly speaking this is a puzzle (p. 838) about unattended peripheral vision). ${ }^{13}$ There is significant intuitive appeal to the claim that peripheral vision cannot sustain perceptual demonstrative thought. For (it seems), a perceptual link that can sustain perceptual demonstrative thought about $o$ must at least present $o$ as distinct from the objects around it. And objects with which we have peripheral vision are not presented as sharply distinct from one another. (Consider how you will do if you try to describe what you can see in peripheral vision at the same time as you read these words. Your peripheral perceptual feed will let you do quite well at statements 


\section{Perception and Demonstratives}

of gross macroscopic property instantiation: 'There is something pale coloured over there'; 'There is something with sharp edges'; 'There is something moving'. And you will be better than chance at putting gross macroscopic properties together ('The sharpedged thing is moving'; 'The pale thing is curved'). But, if you are relying on peripheral vision alone, you will also make many mistakes about which properties go together as properties of the same object. ${ }^{14}$ And any fine detail you add to your account will have to come from either guesswork or prior knowledge.)

However, we need a more-than-just-intuitive story about why peripheral vision cannot sustain perceptual demonstrative thought. And the case of peripheral vision also raises yet another continuum problem. On the face of things, there are degrees of perceptual focus and peripherality. ${ }^{15}$ What degree of centrality to perceptual focus does perceptual demonstrative thought require?

\section{Sixth puzzle-awareness ${ }^{16}$}

The sixth puzzle is about the relation between perceptual demonstrative thought and conscious awareness.

It is a widespread (though comparatively recent) observation that the perceptual system can generate a quite rich information feed even though the subject has no awareness of the object from which the information is derived. For example, subjects with a specific type of brain damage can give, on the basis of visual contact alone, very reliable forcedchoice answers to questions about the properties of objects they are not aware of seeing. (These are 'blindsight' patients. Blindsight is commonly explained as involving information delivery without consciousness. ${ }^{17}$ ) There are also non-pathological cases of this kind. These are cases of 'subliminal' information delivery, where perceptual contact with a thing is too brief to yield awareness, but the fact that the subject has received information from the brief perceptual contact shows up in other aspects of his or her behaviour. (For example, subliminal (p. 839) exposure to a word or to a familiar face has measureable impact how the subject behaves next. $)^{18}$

But the possibility of perceptual information delivery without perceptual awareness raises immediate questions that a right account of how perception enables perceptual demonstrative thought should enable us to answer. In central cases, the perceptual link that enables perceptual demonstrative thought delivers both information and awareness.

But is the 'awareness' part playing a necessary aboutness-securing role, or could there be cases (for us, or for subjects like us, or perhaps for subjects radically different from us) where perceptual demonstrative thought is enabled by a perceptual link that delivers information alone? 


\section{Perception and Demonstratives}

\section{Seventh puzzle-emptiness}

The seventh puzzle concerns what to say about cases which seem, at first sight, to involve perceptual demonstrative aboutness failure. Here are two cases of this kind:

CASE 4-Your experience is indistinguishable by you from the experience you would have if you were looking at an orange rolling along the table in front of you. You form the belief you would express by saying 'That is an orange'. In fact you are hallucinating -there is no orange there for you to experience.

CASE 5-It seems to you that you are looking at a rectangular thing in the middle distance. You form the belief you would express by saying 'That is rectangular'. In fact, your experience as of a rectangular thing in the middle distance is caused by a freak combination of a speck on your glasses and a tree on the horizon.

In each of these cases, you have an experience indistinguishable by you from the experience you would have in a case where a perceptual link with an object does sustain perceptual demonstrative thought. In each case you form a thought you would express using 'that', and which is indistinguishable by you from a perceptual demonstrative thought. And in each case it seems plausible that there is nothing your thought is about. But does it follow that there can be perceptual demonstrative thoughts about nothing? What are the implications of a decision on this issue for the question of how perceptual demonstrative aboutness-fixing works?

\section{Descriptivist Theories vs. Acquaintance Theo- ries}

Accounts of how perception enables perceptual demonstrative thought divide into descriptivist theories and acquaintance theories. This section introduces the two types of view, and consolidates the contrast between them by saying a little about the responses to the puzzles from section 1 that each generates. (p. 840)

\section{Descriptivist theories}

According to a 'descriptivist theory' of perceptual demonstrative thought, a perceptual link with $o$ enables perceptual demonstrative thought about $o$ by putting the subject in a position to grasp a descriptive condition that $o$ satisfies. (In general, a 'descriptivist theory' of thoughts of a kind is a theory according to which being in a position to have a thought of the kind about $o$ involves grasping, or being in a position to come to grasp, a descriptive condition that $o$ satisfies. Descriptivism about perceptual demonstrative thought is a special case of this kind of view. A descriptivist about perceptual demonstratives might be motivated either by 'global descriptivism'-the view that all aboutness-fixing is descriptive-or by specific arguments for descriptivism in the perceptual demonstrative case.) 


\section{Perception and Demonstratives}

Different descriptivist views are generated by different accounts of the aboutness-fixing description. For example, philosophers have upheld each of the following (this is not an exhaustive list).

Traditional descriptivism about perceptual demonstrative thought-In a central case, S's perceptual link enables perceptual demonstrative thought about an object by providing $\mathrm{S}$ with a specification of macroscopic observable properties. The specification will be of form 'the thing of shape $F_{1}$, colour $F_{2}$, position $F_{3}$, degree of motion $F_{4}$, size $F_{5} \ldots$ ' (with the list completed by specifications of other kinds of property, and no kind of property having to appear on the list). 'That'-beliefs formed on the basis of the perceptual link are about $o$ iff $o$ is the unique object that has all (or most of the most important) properties in the specification. ${ }^{19}$

Sortal descriptivism about perceptual demonstrative thought-In a central case, S's perceptual link with $o$ enables perceptual demonstrative thought about $o$ by putting $\mathrm{S}$ in a position to grasp a descriptive condition of form 'the thing of sort $\sigma$ at position p' which $o$ satisfies. $^{20}$

Reflexive descriptivism about perceptual demonstrative thought-In a central case, S's perceptual link with $o$ enables perceptual demonstrative thought about $o$ by providing $\mathrm{S}$ with grasp of a descriptive condition which $o$ satisfies, where this condition mentions either the perceptual link or the experience it delivers, for example, the condition might be 'the object at the end of this perceptual link' or 'the object causing this experience'. ${ }^{21}$

One way to bring out the important similarities and differences between these descriptivist views is in terms of the responses they generate to the puzzles from section 1.

Let us start with the emptiness puzzle. According to all three descriptivist views, thinking a perceptual demonstrative thought involves (actual or potential) grasp of an aboutnessfixing description, and the thought is about $o$ iff $o$ is the description's satisfier. But it takes some squirming to formulate a descriptive condition grasp of which entails the (p. 841) existence of an object that satisfies it. So the most obvious forms of descriptivism about perceptual demonstrative thought (including the three I have sketched) all entail that a perceptual feed might enable grasp of an aboutness-fixing description with no satisfier. For descriptivist views that have this consequence, there is at least an intuitive sense in which a perceptual demonstrative thought may be 'available' even though there is nothing it is about. (There are still hard questions about whether the thoughts a subject forms in cases like Case 4 and Case 5 are false (the alternative is to say that they have no truth values) but addressing these questions requires engagement with issues about the relationship between aboutness-fixing and truth-conditions that I cannot discuss here. ${ }^{22}$ )

I shall give a brief indication of how the other puzzles come out under each descriptivist view in turn.

A traditional descriptivist's response to the puzzles about directness and comprehensiveness will be to say that a perceptual link is direct and comprehensive enough to sustain 


\section{Perception and Demonstratives}

perceptual demonstrative reference as long as it provides the subject with a (sufficiently rich) range of observable macroscopic property information that the object matches. Traditional descriptivism also generates a solution to the puzzle about category: there can be perceptual demonstrative thought about any particular for which a perceptual link can deliver grasp of the traditional descriptivist's favoured model of aboutness-fixing description. So if perceptual links with times, places, and mereological gryphons ('things' that are the mereological sums of parts of distinct objects) can deliver grasp of this kind of description, there can be perceptual demonstrative thought about them. Similarly, a traditional descriptivist's response to the puzzle about focus will be to say that peripheral vision does not sustain perceptual demonstrative thought because a peripheral perceptual link with $o$ does not enable the subject to formulate a sufficiently rich descriptive condition.

With respect to the puzzle about classification, traditional descriptivism is an anti-sortalist view-a traditional descriptivist maintains that aboutness for a perceptual demonstrative thought can be determined just by a suitably wide match between the subject's beliefs and the object's properties, with no one property of the object's having to feature in the list of its properties that the subject gets right..

Finally, with respect to the awareness puzzle, a traditional descriptivist's view will depend on whether he or she thinks a perceptual link can provide grasp of a suitably rich description without also delivering awareness.

In contrast, a sortal descriptivist will say that a perceptual link with $o$ is direct and comprehensive enough to sustain perceptual demonstrative thought about $o$ iff it puts the subject in a position to locate $o$ and discover its kind. So, for example, the sortal descriptivist has a reason to say that there can be demonstrative reference to things seen in mirrors but not to things seen on television: a mirror-mediated perceptual link with a thing does, while a television-mediated link does not put you in a position (without any information not transmitted through the link) to discover the object's location. ${ }^{23}$ And for the case of comprehension, a sortal descriptivist will say that a perceptual link that might involve immediate contact with only the facing surface of a three-dimensional object puts you in a position to refer to the whole object because it is the whole object that your sortal concept classifies. (p. 842)

The sortal descriptivist's responses to the puzzles of focus and awareness will depend on his or her view of whether an unfocused (non-attentional) perceptual link, on the one hand, and a perceptual link that delivers information without awareness, on the other, can enable sortal classification. On the face of things, it is implausible that a merely peripheral perceptual link with an object can deliver precise or detailed enough information to enable sortal classification. So the sortal descriptivist has grounds to deny that an unfocused perceptual link with an object can put a subject in a postion to have perceptual demonstrative thoughts about it. The question of whether a perceptual link that does not deliver awareness can enable sortal classification is more complex, so let us rest with not- 


\section{Perception and Demonstratives}

ing that the answer to this question will determine the sortal descriptivists's response to the awareness puzzle.

Finally, there can be no surprises about the sortal descriptivist's response to the puzzle about classification: perceptual demonstrative thought, on this view, does rest on the capacity for sortal classification.

(What exactly a sortal descriptivist will say about the category puzzle depends on how his or her sortalism is motivated. This is too complicated an issue to dabble in here.)

For a reflexive descriptivist, the solutions to the puzzles will depend on the nature of the proposed reflexive descriptive condition. For example, if the descriptive condition is the object this perceptual link is focused on', perceptual demonstrative thought on the basis of peripheral vision will be ruled out automatically because a peripheral perceptual link is not focused. In contrast, if the favoured descriptive condition is 'the cause of this experience', there seems to be no barrier to perceptual demonstrative thought on the basis of a merely peripheral perceptual link. Again, a reflexive descriptivist favouring the first kind of descriptive condition will say that an indirect perceptual link can sustain perceptual demonstrative thought iff it is focused (so that the burden in saying whether there can be perceptual demonstrative thought about an object seen in a mirror is shifted to the question of whether the perceptual link in this case is focused on the object or its reflection). In contrast, for a reflexive descriptivist favouring the second kind of descriptive condition, the burden will shift to the question of whether the object or its reflection is the cause of the experience. For the kinds of reflexive descriptivism I have mentioned so far, grasp of the descriptive condition requires that the perceptual link be delivering awareness. But a reflexive descriptivist might step back from this result by formulating a different aboutness-fixing description, for example, 'the object that is causing me to hold these beliefs and respond in these ways'.

\section{Acquaintance-theoretic views}

The notion of 'acquaintance' has both a negative and a positive characterization in the philosophical tradition:

Negative characterization of 'acquaintance'-S is 'acquainted' with $o$ iff $S$ is in a position to think about $o$ in virtue of a perceptual link with $o$, and independently of actual or potential grasp of any descriptive condition that $o$ satisfies.

Positive characterization of 'acquaintance'-S is 'acquainted' with $o$ iff $S$ is in a position to think about $o$ because $\mathrm{S}$ has a perceptual link with $o$ that enables $\mathrm{S}$ to have thoughts that are directly about $o$.

(p. 843)

One of the problems in developing an acquaintance-theoretic view is to explain how the notion of 'directness' that figures in the positive characterization is to be understood. ${ }^{24}$ 


\section{Perception and Demonstratives}

An explanation that collapses the positive characterization into the negative characterization is to say that $\mathrm{S}$ is thinking 'directly' about $o$ iff $\mathrm{S}$ has a thought about $o$ whose aboutness is not secured by S's actual or potential grasp of an aboutness-fixing description that $o$ satisfies. $^{25}$

Another possibility is to explain acquaintance-theoretic 'directness' in terms of the claim that acquaintance-based thoughts are formed in immediate response to perception. An acquaintance theorist making this move will say that your 'That is rolling' thought is formed in cognitively unmediated response to your perceptual information feed (it is formed by taking what this feed delivers at face value), and that the aboutness-fixing story about this kind of thought is a story about why a thought formed in this way should count as 'about' the thing at the end of the perceptual link that gives rise to it. ${ }^{26}$

A third possible move is to try to explain the relevant notion of directness in terms of the acquaintance theorist's characteristic response to the emptiness puzzle. If (as the acquaintance theorist maintains) a central-case perceptual link does its thought-enabling work by establishing a direct 'aboutness' relation between the subject and the thing at the end of the perceptual link, if there is no thing at the end of the perceptual link there will be no thought enabling and (therefore) no thought. Philosophers trying to elucidate the acquaintance-theoretic 'directness' in this way have said that thoughts made available by acquaintance with objects are 'object-dependent' thoughts-thoughts which (in an intuitive sense of 'available') are not available if there are no objects they are about. ${ }^{27}$

(One interesting question for philosophers working on acquaintance-theoretic views is that of the extent to which these three accounts of 'directness' coincide.)

In the absence of more detail about what an acquaintance-theoretic view might look like, we are not in a position to see how acquaintance theorists will respond to the other puzzles from section 1 . I shall say more about this in section 4 .

Note that an acquaintance theorist should allow that a perceptual link with $o$ that puts S in a position to think about $o$ might also enable $S$ to grasp a range of descriptive conditions that $o$ satisfies, for example, 'the object I am now thinking about'; 'the object that is the cause of this experience'; or (in a central case, where the viewing conditions are good) 'the object having such-and-such macroscopic properties'. The acquaintance theorist's point is just that it is not by enabling grasp of these descriptive conditions that a perceptual link that enables perceptual demonstrative thought does its aboutness-fixing work. 


\section{(p. 844) 3 The Traditional View of What Cognitively Unaided Perception Delivers, and how it Skews the Traditional Debate about Perception and Demonstratives}

Let us return to our example of a central-case perceptual demonstrative thought. You are looking at an orange as it rolls along the table in front of you in a situation devoid of cognitive or perceptual funny-business. You form the belief you would express by saying 'That is rolling'. The fundamental question for accounts of how perception enables perceptual demonstrative thought is the question of how your perceptual link with the object secures its status as the thing your belief is about.

Any answer to this question will need three components:

First component-an account of how belief formation on the basis of a perceptual link works.

Second component-a general account of what it takes for a belief to be 'about' a particular thing.

Third component-an explanation of how, given the first component, a central case of belief formation on the basis of a perceptual link with $o$ meets the requirements for the belief to be about $o$ entailed by the second component.

The second and third components here are irredeemably philosophical. But at least part of what is required of the first component is an empirical story: a story about the causal pathway by which our perceptual systems deliver perceptual experiences to which our cognitive systems respond by forming beliefs. So an account of how perception enables perceptual demonstrative thought must incorporate an empirical element.

The mainstream traditional debate about perception and demonstratives got its empirical element from a less than reputable source. Philosophers participating in this debate ${ }^{28}$ took it that the path to formation of central-case perceptual demonstrative beliefs involves introspectively discernible stages: perception makes its contribution; then cognition goes to work on what perception delivers; the boundary between what is given in perception and what must be worked out by cognition is a boundary that can be discerned by each of us from within. And these philosophers claimed that what is delivered by the first (perception-only) stage of this process, though phenomenally rich, is structurally poor. The suggestion was that cognitively unaided perception delivers a succession of qualitative seemings. These seemings have spatial structure in that they fill the visual field: each point in the visual field has a colour; same-coloured adjacent points result in the appearance of a patchwork of coloured shapes. And the succession of qualitative seemings has temporal structure: coloured patchworks succeed one another. But this is all the structure (p. 845) that cognitively unaided perceptual experience has. On this traditional view, the kind of account that would come to mind most readily if you were asked to say what you see ('It looks like an orange round thing is rolling from half-shade into full 


\section{Perception and Demonstratives}

light') does not capture what perception delivers. It captures the output of cognitive processing brought to bear on the raw, comparatively unstructured, perceptual feed.

This traditional view has had an impact on the debate about perceptual demonstratives that is too various and pervasive to survey here. But I think it is fair to say that its most important result has been the skewing of the debate about the viability of acquaintancetheoretic views. For the traditional view makes it very hard to see how an acquaintancetheoretic view could be made to work. To see why, consider the following three claims

(A) Cognitively unaided perception delivers an information feed that is too unstructured to sustain the claim that our perceptual experiences 'represent' or are 'of' ordinary three-dimensional objects and their macroscopic observable properties. (Consequence of the traditional view)

(B) We form perceptual demonstrative thoughts by taking what perception delivers at face value. (Acquaintance-theoretic commitment)

(C) Central case perceptual demonstrative thoughts are about ordinary three- dimensional material objects. (Consequence of the definition of 'perceptual demonstrative thought')

(A), (B), and (C) are inconsistent. But (C) is a consequence of the definition of 'perceptual demonstrative thought'. So if (A) is assumed, (B) will have to go.

The inconsistency between (A), (B), and (C) brings out why the traditional view presents a barrier to acquaintance-theoretic views that explain 'directness' in terms of direct uptake of what is delivered by perception. Other ways of explaining acquaintance-theoretic 'directness' will bring the tension between the traditional view and acquaintance theories to the surface in other ways.

\section{The New Debate}

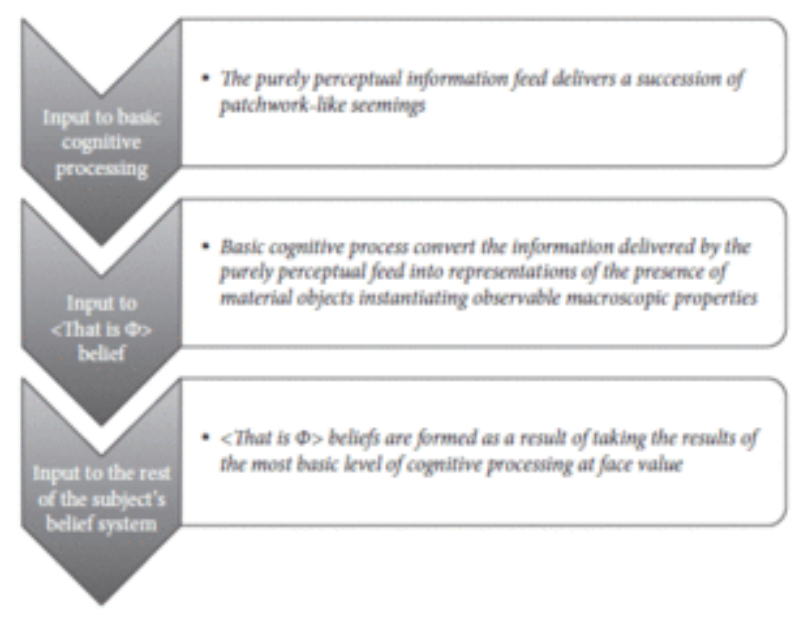

Fig. 43.1 The traditional view. 


\section{Perception and Demonstratives}

The traditional view took as empirical fact something that its proponents found plausible in their own cases, and expected each of us to find plausible in ours. But claims about matters of empirical fact are subject to empirical falsification. And one of the morals philosophers have been forced to draw from the growing flood of experimental findings about perception is that the traditional view is false. In particular, findings about objectdirected attention ${ }^{29}$ and the ways that the perceptual system binds features together as belonging to the same object establish that the perceptual system does not deliver a patchwork which must then be parsed into particular things by thought-level processes. And findings about perceptual constancy ${ }^{30}$ establish that the property information the perceptual (p. 846) system delivers is not mere two-dimensional patchwork-level information. Rather, the step to representation of observable macroscopic properties (properties like three-dimensional shape; size; colour; and motion or rest) is made by perceptual processing that is already complete before cognition comes to the table. ${ }^{31}$

The two charts (Figures 43.1 and 43.2) summarize the difference this step beyond the traditional view makes from the point of view of an account of the causal pathway from perceptual contact with an object to formation of perceptual demonstrative beliefs.

I do not think it is an exaggeration to say that the step to the post-traditional view opens up the possibility of a revolution in the debate about how perception enables perceptual demonstrative thought. ${ }^{32}$ Though the impact of this step redounds through the full range of questions considered in this chapter, it is most obvious with respect to the point about skewing of the description-theoretic vs. acquaintance-theoretic debate from the end of section 3. For with the traditional view gone, (A) in the inconsistent triad laid out above is gone too, and with (A) gone, the acquaintance theorist can look anew for a view that upholds both (B) and (C).

So the move away from the traditional view redefines the terrain on which the discussion about perception and demonstratives must take place. I shall give a brief indication of what I take to be the central issues in the new debate.

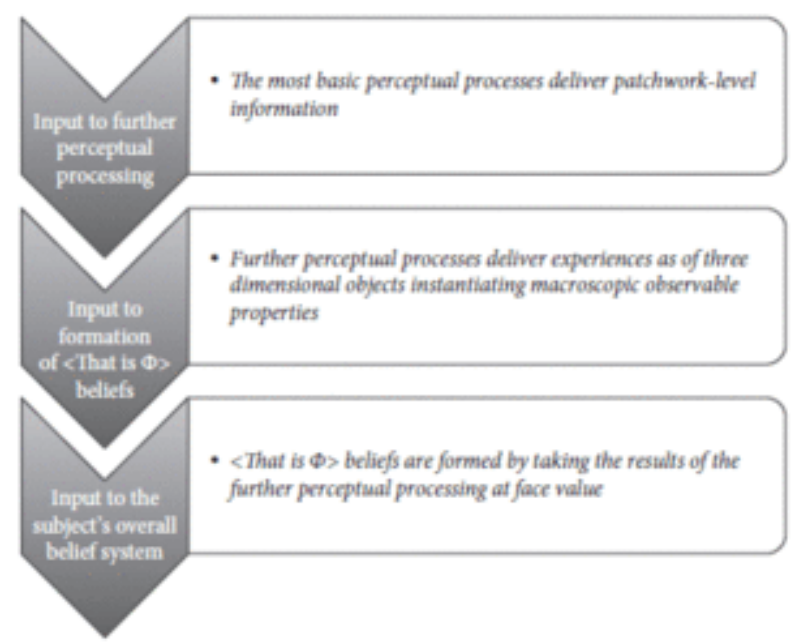

Fig. 43.2 The post-traditional view. 


\section{Perception and Demonstratives}

I suggest that the first step in the new debate lies with an empirical claim about the pathway to $<$ That is $\Phi>$ belief described by the post-traditional view. To motivate this claim, suppose you are looking at a strange object whose shape properties and reflectance-oflight properties (p. 847) are radically anomalous. This object starts out round, then, in the space of a few seconds, compresses into an ellipse, then into a skinnier ellipse, then into a flat rectangle, before expanding through shades of ellipticality back into a circle. Meanwhile, the object absorbs and reflects light in a non-standard way. The overall result is that the shape and orientation cues picked up by your visual system are the same as those it picks up when you look at a constantly shaped disc rotating on an axis that passes through its centre parallel to its surface (a coin rotating on a vertical spit). In this case, the 'further perceptual processing' mentioned in the middle box of Figure 43.2 makes the same calculations as it does in a case where you actually are seeing a rotating disc. (That is why you end up with an experience indistinguishable by you from a 'rotating disc' experience.) But, given the category of object you are looking at, the $<$ That is $\Phi>$ beliefs you form based on these property calculations will not tend to get the object's properties right.

This conclusion generalizes. The visual system uses a series of algorithms to calculate the perceptual property information that serves as input for formation of $<$ That is $\Phi>$ belief. These algorithms result in reliable belief formation only given perceptual encounters with objects that behave the way ordinary objects behave in ordinary circumstances.

So the post-traditional view generates an empirical claim about the relation between $<$ That is $\Phi>$ beliefs and the object at the end of the perceptual link that gives rise to them:

An empirical claim about the formation of perceptual demonstrative beliefs-The pathway by which perceptual demonstrative beliefs are formed produces beliefs that tend to match the properties of the object at the other end of the perceptual link iff it is an ordinary material object.

I suggest that perceptual links with ordinary objects enable us to have perceptual demonstrative thoughts about them because they deliver beliefs that are reliable in this (p. 848) sense: beliefs that tend to match what the object at the end of the perceptual link is like. And I suggest that, in a post-traditional framework, the fundamental question about perception and demonstratives-the question of how perceptual contact with objects enables perceptual demonstrative thoughts about them-becomes the question of how to build an account of perceptual demonstrative aboutness-fixing around this central claim about reliability.

To see why this suggestion is plausible, let us step back for a moment from our close focus on aboutness-fixing for perceptual demonstrative thoughts to consider aboutness-fixing for thoughts in general. (Recall that one element in an account of perceptual demonstrative aboutness-fixing is going to be a general background view of how aboutness-fix- 


\section{Perception and Demonstratives}

ing works: this is the second component identified at the start of section 3.) Here are two widely accepted elements of this more general discussion:

A claim connecting truth and justification-In general, justification homes in on truth, so that if you have sufficient justification to make it rational for you to form a belief, you will be unlucky if the belief is not true and not merely lucky if it is.

A claim connecting what a belief is about with what it would take for it to be true - A body of beliefs is about an object iff their truth or falsity depends on what the object is like.

The first claim coordinates aboutness and truth. The second coordinates truth and justification. Putting the two coordinating claims together we get an argument for a third claim coordinating aboutness and justification (aboutness and truth + truth and justification $\rightarrow$ aboutness and justification):

A claim connecting aboutness and justification-A body of beliefs is about an object iff justification for holding them homes in on getting the object's properties right.

(For example, this claim says that the beliefs you would express using the proper name 'Barack Obama' are about Obama iff, in general, if it is rational for you to hold the belief you would express by saying rBarack Obama is $\Phi\urcorner$, it will not just be a matter of luck whether Obama is $\Phi$-given your justification for the belief, you will be unlucky if Obama is not $\Phi$ and not merely lucky if he is. ${ }^{33}$ I suppress both the details of how the third claim follows from the first two, and any discussion of how the intuitive notions of 'homing in on truth' and being 'lucky' or 'unlucky' in the relevant sense are to be made precise. ${ }^{34}$ )

The claim connecting aboutness and justification can be restated as a claim about the kind of relation that suffices to fix aboutness. For the special case of perceptual demonstrative aboutness-fixing, the account can be summarized like this:

A claim about perceptual demonstrative aboutness-fixing-A perceptual link with $o$ enables perceptual demonstrative thought about $o$ by securing the result that $<$ That is $\Phi>$ beliefs justified on the basis of this link will tend to get $o$ 's properties right.

(p. 849)

Now let us place the empirical claim and the claim about perceptual demonstrative aboutness-fixing side by side: 


\section{The empirical claim}

As long as the object at the other end of a perceptual link is an ordinary object, the ordinary route to formation of $<$ That is $\Phi>$ beliefs will tend to deliver beliefs that match the object's properties.

\section{The claim about perceptual demonstrative aboutness-fixing}

A perceptual link with an object enables perceptual demonstrative thought about it by securing the result that <That is $\Phi>$ beliefs justified on the basis of the link tend to match what the object is like.

The left-hand claim here is a 'descriptive' or 'is' claim (it describes a result that a causal process usually generates). The right-hand claim is a 'normative' or 'ought' claim (it describes a result that will tend to be generated if subjects form only beliefs that conform to a specific normative condition (beliefs that the subject ought to form given justification on the basis of perception)). To get from the first ('is') claim to the second ('ought') claim, we need a reason to say that the ordinary route to formation of <That is $\Phi>$ beliefs is justification conferring. So, given the left-hand claim, the problem in explaining how a perceptual link with an object enables a perceptual demonstrative thought about it reduces to the problem of explaining why perceptual demonstrative beliefs formed by ordinary means are justified: different views of how perceptual demonstrative beliefs are justified will coordinate with different views of how perceptual demonstrative aboutness is secured.

The question of how perception justifies perception-based beliefs has its own entries elsewhere in this volume. ${ }^{35}$ So, rather than embarking on a discussion of this topic here, I shall close by saying a little about the more immediate consequences of the post-traditional approach I have suggested for the puzzles from section 1. I should stress that the following remarks are not intended as comprehensive solutions to the puzzles. They are intended as a first indication of what a solution to each puzzle will look like in the framework I have proposed.

Let us consider the category puzzle first. This is the puzzle of whether there can be perceptual demonstrative thought about particulars other than ordinary material objects, for example, events, times, places, shadows, ripples, or mereological gryphons. According to the post-traditional approach, the mechanism of perceptual demonstrative aboutness-fixing is keyed to ordinary objects. For it is if, but only if, the object at the end of the perceptual link is an ordinary object that the ordinary route to formation of <That is $\Phi>$ beliefs will tend to produce beliefs that match the object's properties. So it is if, but only if, the object at the end of the perceptual link is an ordinary object that it will be the object the beliefs formed by these means are about. If you are having an experience indistinguishable by you from an experience of looking at an ordinary thing when (unbeknownst to you) the 'visual object'36 you are looking at is a shadow or a ripple or a (p. 850) mereological gryphon, and if you go along with appearances and form a belief you would express by 


\section{Perception and Demonstratives}

saying < That is $\Phi>$ you are not having a perceptual demonstrative belief about the visual object from which your perceptual information is derived; you are having a belief about nothing. (Note that the point is not that a perceptual link cannot put you in a position to think about a particular that is not an ordinary object. It is just that the mechanism of aboutness-fixing in this kind of case is not the mechanism of perceptual demonstrative aboutness fixing. Note also that the post-traditional approach generates a way to refine our grasp of the boundaries of the category of ordinary objects: an 'ordinary object' (given this approach) is just a potential object of perceptual demonstrative thought; an object whose properties the ordinary mechanisms for formation of perceptual demonstrative belief will tend to get right.)

Now consider the directness puzzle. This is the puzzle of how causally serpentine a perceptual link with an object may be while still sustaining perceptual demonstrative reference to it. For example, one standard case discussed by philosophers interested in perception and demonstratives is the case of an object seen in a mirror: is a <That is $\Phi>$ thought formed on the basis of this kind of perceptual feed about the reflected object or its reflection or neither? The approach I have recommended generates an answer to this question, and a general rubric for addressing similar ones. Your < That is $\Phi>$ thought is about the object, not the reflection, because it is the object's properties, not the reflection's, that you will tend to get right if you form beliefs by taking what the perceptual feed delivers at face value. If your are watching an orange roll in a mirror, you will form $<$ That is spherical $>$; $<$ That is rolling $>$; $<$ That is solid $>$; and $<$ That is about to fall $>$ beliefs. Given the way they are formed, these beliefs will almost all match what the orange, not the reflection, is like. (Your beliefs about the direction in which the thing is located and its orientation will tend to match the reflection, but these are exceptions to the rule). And this pattern holds in general: a perceptual link with an object is direct enough to sustain perceptual demonstrative reference to it iff $<$ That is $\Phi>$ beliefs formed by direct uptake from what the link delivers will tend to produce beliefs that match the object's properties.

The comprehensiveness puzzle is the puzzle of how much of an object you have to be in perceptual contact with if you are to form perceptual demonstrative thoughts about it. The approach I have suggested explains why perceptual contact with an ordinary object's facing surfaces enables perceptual demonstrative reference to all of it: the path to formation of $<$ That is $\Phi>$ beliefs produces beliefs that tend to match what the whole object, not its facing surface, is like. And, again, this rubric generalizes to other comprehensiveness puzzle cases: perceptual contact with a part of $\mathrm{X}$ will sustain perceptual demonstrative thought about all of $\mathrm{X}$ wherever this same pattern (<That is $\Phi>$ beliefs formed by uptake of what the perceptual link delivers tend to match X's properties) holds.

The classification puzzle concerns whether the capacity for perceptual demonstrative thought depends on the capacity for sortal classification. The post-traditional approach generates an (at least initial) 'No' answer to this question. According to this approach, a perceptual link with an ordinary object enables perceptual demonstrative thought about it because the ordinary route to formation of <That is $\Phi>$ beliefs on the basis of the link 


\section{Perception and Demonstratives}

tends to get the object's properties right. But on the face of things this route to formation of <That is $\Phi>$ beliefs does not involve sortal classification. So, on the face of things, perceptual demonstrative aboutness-fixing does not involve sortal classification either.

(p. 851)

The focus puzzle is the puzzle of whether (and if not why not) we can have perceptual demonstrative thoughts about objects in peripheral vision. Recall that one of the difficulties involved in addressing this puzzle is that there are degrees of peripherality, so we seem to have to ask how much focus perceptual demonstrative aboutness-fixing requires. But according to the post-traditional approach, a perceptual link that secures perceptual demonstrative aboutness does so in virtue of the fact that beliefs formed on the basis of the link will reliably match what the object at the end of the link is like. And the reliability of a perceptual link depends on the degree to which it is focused. So we have a principle to use in addressing the focus puzzle. A perceptual link will enable perceptual demonstrative thought iff it is sufficiently focused on an object to put the information it delivers above an appropriate reliability threshold. Peripheral vision cannot sustain perceptual demonstrative thought because merely peripheral perceptual feeds do not generate $<$ That is $\Phi>$ beliefs that reliably match what the perceived objects are like.

Finally, consider the awareness puzzle: what role (if any) does perceptual awareness play in enabling perceptual demonstrative thought. The post-traditional view does not generate an immediate response to this puzzle. But it does tell us where to look for one. Perceptual awareness plays an essential role in perceptual demonstrative aboutness-fixing iff it plays an essential role in the justification of $<$ That is $\Phi>$ beliefs formed by ordinary means.

\section{References}

Ayers, M. (1974). 'Individuals without sortals'. Canadian Journal of Philosophy, 4(1), 11348.

Ayers, M. (1997). 'Is "physical object" a sortal concept? A reply to Xu'. Mind and Language, 12(3-4), 393-405.

Campbell, J. (2002). Reference and Consciousness. Oxford: Oxford University Press.

Campbell, J. (2006). 'Does visual reference depend on sortal classification?' Philosophical Studies, 127(2), 221-37.

Campbell, J. (2011). 'Visual attention and the epistemic role of consciousness'. In Mole, Smithies, and Wu, (eds), Attention: Philosophical and Psychological Essays (pp. 323-41). Oxford: Oxford University Press.

Crane, T. (2011). 'The problem of perception'. In Edwards N. Zalta (ed.), The Stanford Encyclopedia of Philosophy (Spring 2011 edn). 


\section{Perception and Demonstratives}

Dehaene, S., Changeux, J.-P., Naccachel, L., Sackur, J., and Sergent, C. (2006). 'Conscious, preconscious, and subliminal processing: a testable taxonomy'. Trends in Cognitive

Science, 10, 204-11.

Dennett, D. (1978). 'Where am I?' In Dennett, Brainstorms: Philosophical Essays on Mind and Psychology. Cambridge, MA: MIT Press.

Dickie, I. (2010). 'We are acquainted with ordinary things'. In Robin Jeshion (ed.), New Essays on Singular Thought (pp. 213-45). Oxford: Oxford Unversity Press.

Dickie, I. (2011a). 'Visual attention fixes demonstrative reference by eliminating referential luck'. In C. Mole, D. Smithies, and W. Wu (eds), Attention: Philosophical and psychological essays (pp. 293-322). Oxford: Oxford University Press.

Dickie, I. (2011b). 'The sortal dependence of demonstrative reference'. European Journal of Philosophy.

Dummett, M. (1973). Frege: Philosophy of language. London: Duckworth. (p. 852)

Dummett, M. (1978). 'Truth'. In Michael Dummett, Truth and Other Enigmas. London: Duckworth.

Evans, G. (1985). 'Understanding demonstratives'. In Gareth Evans (ed.), Collected Papers (pp. 291-321). Oxford: Oxford University Press.

Evans, G. (1982). The Varieties of Reference. Oxford: Oxford University Press.

Frege, G. (1884/1953). The Foundations of Arithmetic, trans. J. L. Austin. Oxford: Blackwell.

Grandy, R. E. (2008). 'Sortals'. In Edward N. Zalta (ed.), The Stanford Encyclopedia of Philosophy (Fall 2008 edn).

Kaplan, D. (1968-9). 'Quantifying in'. Synthese, 19, 178-214.

McDowell, J. (1984). 'De re senses'. Philosophical Quarterly, 34, 283-94.

Matthen, M. (2005). Seeing, Doing, and Knowing. Oxford: Oxford University Press.

Moore, G. E. (1918). 'Some judgements of perception'. Proceedings of the Aristotelian Society, New Series, 19, 1-29.

Moore, G. E. (1962). Commonplace Book 1919-1953. London: Allen and Unwin.

Palmer, S. E. (1999). Vision Science-Photons to Phenomenology. Cambridge, MA: MIT Press.

Quine, W. v. O. (1953). 'Identity, ostension, and hypostasis'. In W. v. O. Quine (ed.), From a Logical Point of View (pp. 65-79). Cambridge, MA: Harvard University Press. 


\section{Perception and Demonstratives}

Quine, W. v. O. (1960). Word and Object. Cambridge, MA: MIT Press.

Quine, W. v. O. (1969). 'Speaking of objects'. In W. v. O. Quine, Ontological Relativity and Other Essays (pp. 1-25). New York: Columbia University Press

Recanati, F. (2012). Mental Files. Oxford: Oxford University Press.

Russell, B. (1912). The Problems of Philosophy. Oxford: Oxford University Press.

Searle, J. (1980). 'Minds, brains, and programs'. Behavioral and Brain Sciences, 3, 41757.

Searle, J.(1983). Intentionality. Cambridge: Cambridge University Press.

Siegel, S. (2010). The Contents of Visual Experience. Oxford: Oxford University Press.

Smithies, D. (2011). 'What is the role of consciousness in demonstrative thought?' Journal of Philosophy, 108, 5-34.

Strawson, P. F. (1950). 'On referring'. Mind, 59, 320-44.

Wiggins, D. (1997). 'Sortal concepts: A reply to Fei Xu'. Mind and Language, 12, 413-21.

Wiggins, D. (2001). Sameness and Substance Renewed. Cambridge: Cambridge University Press.

$\mathrm{Xu}, \mathrm{F}$. (1997). 'From Lot's wife to a pillar of salt: Evidence that physical object is a sortal concept'. Mind and Language, 12, 365-392.

\section{Notes:}

( $\left.{ }^{1}\right)$ See relevant entries in this volume-Simmons, Chapter 4, on early modern philosophy, and Snowdon, Chapter 6, on sense-data.

$\left({ }^{2}\right)$ Views of this kind are an extension of Quine's thesis of the inscrutability of reference. The canonical source for Quine's original arguments for this thesis is Quine, 1960: ch 2. Quine gives a more accessible introduction in Quine, 1969. For a discussion of the inscrutability challenge as it arises for the case of perceptual demonstrative thought, see Campbell, 2002: 216-34.

$\left({ }^{3}\right)$ There are exceptions. See in particular Evans, 1982: ch. 6 (pp. 143-91). For discussion of perception in non-visual modalities, see chapters 15-18 in Part III of this volume. For discussion of multisensory perception, see Bayne and Spence, Chapter 32, this volume.

$\left({ }^{4}\right)$ For discussions of this puzzle, see Evans, 1982: 144, 149-50; Campbell, 2002: 111.

$\left({ }^{5}\right)$ The contemporary discussion of this puzzle starts with Moore, 1918 and 1962: 177. For an influential discussion, see Evans, 1982: 144-45. 


\section{Perception and Demonstratives}

$\left({ }^{6}\right)$ There is a debate about whether this claim should be accepted. See Crane, 2011 for an introduction and references.

$\left({ }^{7}\right)$ Grandy, 2008 provides an informative introduction and references. The contemporary debate on this question traces to Frege, 1953: $§ 53$ (pp. 65-7). There is a related debate about whether sortal properties can be presented in perception. For a 'yes' answer, see Siegel, 2011.

$\left({ }^{8}\right)$ For sortalist views, see Frege, 1953: esp. 28, 59, 62, 66; Quine, 1953; Wiggins, 2001; Evans, 1982: esp. 105-12, 178-9; Dummett, 1973: 73-80, 179-80. There are important differences in motivation between these varieties of sortalism.

$\left({ }^{9}\right)$ For examples like this in the anti-sortalist literature, see Ayers, 1974, 1997; Campbell, 2006.

(10) See Wiggins, 2001: 7, 55-61; Evans, 1982: 178-9. For a discussion of the viability of the standard move, see Dickie, 2011b: $\$ 4$. An alternative move is to say that the reference requires being right about sortal classification, but that the only referentially relevant sortal is something very general like 'physical object'. See Xu, 1997 for a psychologist making this proposal; Wiggins, 1997 and Ayers, 1997 for sortalist and anti-sortalist replies.

(11) For discussion of this puzzle, see Dickie, 2011a: 315-8.

(12) The most thorough discussion of this puzzle to date is in Campbell, 2002.

(13) For an introduction to discussion of perceptual attention see Campbell, Chapter 31, this volume.

(14) For an introduction to empirical results about the relationship between perceptual attention and reliable 'binding' of features as belonging to the same thing, see Palmer, 1999: 556-563.

(15) More accurately, there are 'degrees of perceptual attention'. See Campbell, Chapter 31 , this volume, on attention.

(16) This puzzle was brought into the debate on perception and demonstratives by Campbell (2002). For subsequent discussions, see Campbell, 2011; Dickie, 2011a; Smithies, 2011. The puzzle is connected with general issues about the relationship between conscious awareness and intentionality of the kind most famously raised by Searle (1980).

(17) See Prinz, Chapter 19, this volume.

(18) See Dehaene et al., 2006.

(19) For an approximation to this kind of view, see Russell, 1912: ch. 2, pp. 46-59.

Kaplan's 1969 notion of a 'vivid' name combines traditional descriptivism with a causal link requirement. 


\section{Perception and Demonstratives}

$\left({ }^{20}\right)$ Dummett is a sortal descriptivist about perceptual demonstratives. See for example his 1973: 233. Evans's view in his 1982, ch. 6, is that a perceptual link with an object enables perceptual demonstrative reference to it iff the link gives the subject the 'practical and in principle' capacity to locate an object and discover its kind. Evans denies that this is a descriptivist view. But it is a form of 'sortal descriptivism' in the sense defined here.

$\left({ }^{21}\right)$ Compare Searle, 1983: 225-7.

(22) For two important first moves in this debate, see Strawson, 1950 and Dummett, 1978.

(23) Evans argues like this at 1982: 147-50. See also Dennett, 1978.

(24) For an introduction to the history of attempts to answer this question, see Recanati, 2012: 3-14.

(25) See, for example, Russell, 1912: 46; Matthen, 2005: ch. 13.

$\left({ }^{26}\right)$ This kind of view forms one strand in Evans's account of the 'directness' of perceptual demonstrative aboutnesss-fixing. See for example Evans, 1982: 146 (but remember that Evans's view also incorporates a descriptivist element - see n. 20). The proposals in Campbell, 2002 and Dickie, 2010, 2011a also involve this kind of view of the 'directness' of perceptual demonstrative thought.

$\left({ }^{27}\right)$ For infuential discussions of this idea, see Evans, 1982: esp. 10-33; Evans, 1985; McDowell, 1984.

$\left({ }^{28}\right)$ See Simmons, Chapter 4 , this volume, on early modern views of perception and Casati, Chapter 20, this volume, on object perception. For a recent account of the transition away from the traditional view see Matthen, 2005: ch. 1.

(29) See Campbell, Chapter 31, this volume, on attention.

$\left({ }^{30}\right)$ See Cohen, Chapter 33, this volume.

$\left.{ }^{31}\right)$ For a recent book-length discussion of which properties are represented in perception, see Siegel, 2010.

( $\left.{ }^{32}\right)$ Many others working on these and related issues are of the same mind. Evans's talk of 'perceptual information channels' (1982: ch. 6) is already a step in this direction. See also Campbell, 2002; Matthen, 2005.

$\left.{ }^{33}\right)$ I am using ' $\Phi$ ' as a schematic variable ranging over conceptual representations of properties when it occurs inside pointy brackets and the associated predicates when it occurs in corner quotes. ' $\Phi$ ' ranges over properties, and is braced with ' $\Phi$ ': $\ulcorner$ That is $\Phi$ 1 expresses the thought $<$ That is $\Phi>$, and both are true if the referent of 'that' is $\Phi$.

(34) I provide some of the relevant details in Dickie, 2011a.

(35) See Siegel and Silins Chapter 41, and Brogaard, Chapter 13, this volume. 


\section{Perception and Demonstratives}

$\left({ }^{36}\right)$ This is a psychologists' term used to describe whatever is treated as an object by the visual system.

Imogen Dickie

Imogen Dickie, University of Toronto 